\section{An endgame for tobacco?}

\author{
Kenneth E Warner
}

\begin{abstract}
Since its origins in the 1960s, tobacco control has achieved remarkable success against the scourge of tobacco-produced disease and death. Yet tobacco use, especially cigarette smoking, remains the world's leading cause of preventable premature death and is likely to do so for decades to come. Evidence-based policies seem incapable of substantially hastening the demise of smoking. Slowness in the decline of smoking in developed nations, and increasing smoking in many low- and middle-income countries has sparked interest in novel, even radical 'endgame' strategies to eliminate the toll of tobacco. This paper identifies the principal endgame proposals and, with the other papers in this volume, has the goal of expanding and deepening the endgame conversation by engaging the broader tobacco control community. While we struggle today with often widely divergent perspectives and beliefs about what is possible and how it might be achieved, we all share the same vision of the final words to this story: 'The end'.
\end{abstract}

Since publication of the UK Royal College of Physicians' report on smoking in $1962,{ }^{1}$ and the US surgeon general's report in $1964,{ }^{2}$ progress against the scourge of tobacco-produced disease has been striking: smoking prevalence has declined by half or more in most developed nations. Indeed, when measured in terms of premature deaths averted, ${ }^{3}$ tobacco control is arguably the developed world's single greatest public health success story of the past half century.

Still, tobacco use-and principally, cigarette smoking-remains the leading cause of preventable premature death and illness in all those countries, and it is increasingly achieving that dubious status within low-income and middle-income countries (LMICs). According to WHO, smoking killed 100 million people worldwide in the 20th century, and, with currently anticipated patterns of tobacco consumption, will claim 1 billion lives in the present century, most in LMICs. ${ }^{4}$ The

Correspondence to Kenneth E Warner, Department of Health Management \& Policy, School of Public Health, University of Michigan, 1415 Washington Heights, Ann Arbor, MI 48109-2029, USA; kwarner@umich.edu great successes of many national antismoking campaigns notwithstanding, the pandemic persists. In many developed countries with the most robust tobacco control efforts, the decline in smoking prevalence has slowed to a trickle. Evidence-based policies seem incapable of substantially hastening the demise of smoking in these countries. ${ }^{5}$ In LMICs, smoking is on the rise. The net effect is that, barring more-and more effectivetobacco control, global smoking prevalence will remain between a fifth and a fourth of all adults for at least the next 20 years. ${ }^{6}$ Unless something dramatically different occurs, smoking will continue to be Public Health Enemy \#1 for decades to come, killing millions of people every single year.

This dire prognosis has led several visionaries to propose endgame strategies, novel, even radical approaches to tobacco control that, their proponents believe, hold the potential of dealing smoking a knock-out punch. While these endgame strategies vary widely in methods and aspirations, they share two underlying beliefs: (1) that the status quo is unacceptable and (2) that reducing smoking substantially will require something new, bold and fundamentally different from the tried-and-true. The origins of these proposals lie in a provocative article published in $1994^{7}$ in which Benowitz and Henningfield proposed gradually reducing the nicotine in cigarettes to non-addicting levels. Nearly a decade later, Borland advocated a Regulated Market Model for tobacco that would end direct-to-consumer marketing through the creation of a not-for-profit distribution agency with a harm reduction mandate. ${ }^{8} \mathrm{~A}$ subsequent proposal by Callard and colleagues also called for the removal of the profit incentive by transferring the tobacco market to a non-profit entity. ${ }^{9}$ Only in the past 3 years, however, has the explicit notion of seeking an endgame for cigarette smoking found its way into the scholarly literature. ${ }^{10}$ Ideas range from a sinking lid on supply approach ${ }^{11}$ to prohibiting tobacco consumption by people born in 2000 or later $^{12}$ to outright abolition of smoking. ${ }^{13} 14$

What is needed now is to familiarise the broader tobacco control community with the concept of an endgame and proposals to achieve it-that is the principal purpose of this special supplement-and then to evaluate what might be achieved by the various proposals. The latter requires contemplation of each strategy's potential outcomes, good and undesirable, and the political, legal, ethical, economic, regulatory and social barriers to realising the strategy's implementation. Finally, the very idea of what constitutes the end of the endgame needs to be addressed. Strikingly, to date, there has never been a serious discussion within the tobacco control community about what would constitute a final victory in tobacco control. Would it be a reduction in smoking-produced deaths to, say, $10 \%$ of current levels? Or 5\%? Would it, rather, entail reducing cigarette smoking prevalence to $10 \%$ or $5 \%$ ? Would it require the end of all smoking? Would victory demand the end of all forms of tobacco use? Would it, rather, envision the population's being nicotine-free? Or would the end of the endgame be the attainment of a more modest tobacco harm minimisation objective? ${ }^{15}$

The essence of the endgame requires thinking outside the box. This invites contemplation of a heresy: Is it possible-is it conceivably desirable-to envision a role for industry in striving for the endgame? Philip Morris International has announced its intention to begin selling what sounds like a pulmonary nicotine inhaler in various markets in the next few years. $^{16}$ A true pulmonary nicotine inhaler would be the first of its kind, a highly addictive product that might therefore serve as a satisfactory substitute for cigarettes for a subset of cigarette smokers. (Neither the pharmaceutical inhaler nor current e-cigarettes appear to deliver significant amounts of nicotine to the lung. Rather, their nicotine is absorbed through the oral mucosa, much like nicotine gum or lozenge. ${ }^{17}{ }^{18}$ ) Although nicotine is not risk-free, a nicotine-only product would be dramatically less dangerous than combusted tobacco. Could a true pulmonary inhaler hasten the demise of the cigarette? Could the profit motive contribute to movement toward the end of the horrendous death toll associated with combusted tobacco? A profitable substitute for the cigarette-one that could be taxed, thereby easing governments' revenue concerns-would confront far fewer political barriers than would adoption of any of the 'mainstream' endgame policies.

None of the principal endgame strategies described in this volume involves cooperation with the industry, however. To the contrary, they all directly and substantially threaten the industry's economic 
interests, not to mention its very existence. The barriers to adoption of the principal endgame policies are formidable and may seem insurmountable; but the history of tobacco control suggests that it would be unwise not to contemplate the endgame. As recently as a decade ago, most experts likely would have deemed it inconceivable that today close to 30 entire countries would have completely smoke-free workplaces, including all restaurants and bars. ${ }^{19}$ Australia recently implemented plain packaging, despite fierce industry opposition, ${ }^{20}$ and the country shares with Uruguay ${ }^{21}$ the distinction of leading the march toward graphic warnings that cover the large majority of the front and back of cigarette packs. One of Australia's tobacco control leaders is now promoting the concept of licensing smokers to purchase cigarettes, with a return of licensing fees if they decide to quit. ${ }^{22}$ Novel developments will continue to occur, and we as a public health community will be far better positioned to address them sensibly if we can get ourselves to 'imagine things otherwise,' as this journal's editor has characterised the endgame discussion. ${ }^{10}$ We often lose sight of the fact that to date, tobacco control has cut the toll of tobacco in many countries by well over half of what it would have been. ${ }^{3}$ The remainder will be more challenging. Could one or more endgame strategies expedite the day we cut the toll in half again?

In this supplement, some of the world's most brilliant tobacco control scholars, strategists and activists, including those who originated the principal endgame concepts, offer a wide range of observations pertinent to contemplating the endgame. With other colleagues, these authors gathered together in Ann Arbor, Michigan, last June at a workshop hosted by the University of Michigan School of Public Health to contemplate the very notion of an endgame and to debate the merits of the various endgame proposals brought to light to date. The workshop was sponsored by grants from the American Legacy Foundation and the Robert Wood Johnson Foundation, who also sponsored the development and distribution of this supplement. On behalf of the workshop organisers and participants and the supplement authors, I express our deep gratitude to these visionary organisations for their willingness to encourage thinking outside the box.

The papers published in this volume are not the proceedings of the workshop, although they certainly reflect both the subject matter covered and the diversity of issues and perspectives that characterised

\section{What this study adds}

- The continuing scourge of tobacco-produced disease is unlikely to yield to today's evidence-based interventions. Several public health visionaries have introduced tobacco endgame proposals with the goal of substantially reducing, and perhaps entirely eliminating, the toll of tobacco.

- Endgame proposals include administrative mechanisms to remove the profit incentive from selling tobacco products, regulation requiring reduction of the nicotine in cigarettes to non-addicting levels, imposition of a 'sinking lid' on the supply of tobacco, prohibition of possession of tobacco products by all individuals born in or after the year 2000, and outright abolition of commercial tobacco product manufacture and sale.

- While the endgame proposals represent radical thinking, remarkable innovation has characterised tobacco control over just the past decade, with smoke-free workplace laws, encompassing all restaurants and bars, in nearly 30 countries, large graphic warnings on cigarette packs in dozens of countries and plain packaging initiated in Australia.

the lively proceedings. A subset of the authors in this volume were given specific assignments. The originators of the core endgame strategies were all asked to convey the essence of their strategies and to comment on what they have learned about them in the months and years since they were first published. ${ }^{23-28}$ Four of the supplement authors will be unfamiliar to most members of the tobacco control community. Scholars who have not focused on tobacco control, they were selected precisely because they could take their well-established disciplinary expertise-in political science, ${ }^{29}$ organisation theory, ${ }^{30}$ public policy and economics, ${ }^{31}$ and law and ethics ${ }^{32}$ - and apply it to the endgame discussion without the preconceptions or biases that occasionally afflict those of us who have devoted our careers to tobacco control. Their insights were enormously valuable to the workshop discussions and should be equally enlightening to readers of this supplement.

With one exception, a doctoral student who helped organise the workshop, ${ }^{33}$ the other authors are all highly regarded members of the tobacco control community who were invited to offer whatever thoughts they wished to share on whatever endgame issues struck them as most important or most intriguing. Their commentaries range from the aspirational (the very nature of the endgame notion) to the practical, from the political to the philosophical and ethical.

The goal of the workshop-and indeed the goal of this supplement-was never to produce a consensus on any of the challenging questions that pervade the subject of the tobacco endgame; it is far too early to do so. Rather, as one participant put it, the intent of the workshop was to serve as 'an intellectual ice-breaker' for the field of endgame studies. We hope this supplement will play a similar role for the broader tobacco control community, opening up the debate, enlisting a wider array of tobacco control and public health professionals, and thereby hastening the determination of answers to the challenging questions. While we struggle today with often widely divergent perspectives and beliefs, we all share the same vision of the final words to this story: 'The end'.

Contributors KEW organised the workshop which was the basis for this supplement and wrote this commentary.

Funding This work was funded by grant \#69489 to the University of Michigan from the Robert Wood Johnson Foundation of Princeton, NJ.

\section{Competing interests None.}

Provenance and peer review Commissioned; internally peer reviewed.

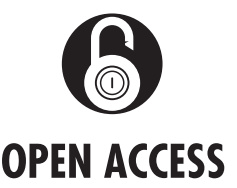

Open Access This is an Open Access article distributed in accordance with the Creative Commons Attribution Non Commercial (CC BY-NC 3.0) license, which permits others to distribute, remix, adapt, build upon this work non-commercially, and license their derivative works on different terms, provided the original work is properly cited and the use is noncommercial. See: http://creativecommons.org/licenses/ by-nc/3.0/

To cite Warner KE. Tob Control 2013;22:i3-i5.

Received 26 January 2013

Accepted 21 February 2013

Tob Control 2013;22:i3-i5

doi:10.1136/tobaccocontrol-2013-050989

\section{REFERENCES}

1 Royal College of Physicians. Summary of a report of the Royal College of Physicians of London on smoking in relation to cancer of the lung and other 
diseases. London: Pitman Medical Publishing Co. Ltd., 1962. http://www.rcplondon.ac.uk/sites/default/ files/smoking-and-health-1962.pdf (accessed 26 Jan 2013).

2 U.S. Public Health Service. Smoking and Health: Report of the Advisory Committee to the Surgeon General of the United States. U-23 Department of Health, Education, and Welfare. Public Health Service Publication No. 1103. 1964. http://profiles.nlm.nih.gov/NN/B/C/X/B/ (accessed 26 Jan 2013).

3 Warner KE. Effects of the antismoking campaign: an update. Amer J Public Health 1989;79:144-51.

4 World Health Organization, Tobacco Free Initiative. Tobacco facts. http://www. who.int/tobacco/mpower/ tobacco_facts/en/index.html (accessed 25 Jan 2013).

5 Warner KE, Mendez D. Tobacco control policy in developed countries: today, yesterday and tomorrow. Nicotine Tob Res 2010;12:876-87.

6 Mendez D, Alshanqeety 0 , Warner KE. The potential impact of smoking control policies on future global smoking trends. Tob Control 2013;22:46-51.

7 Benowitz NL, Henningfield JE. Establishing a nicotine threshold for addiction. The implications for tobacco regulation. New Engl I Med 1994;331:123-5.

8 Borland R. A strategy for controlling the marketing of tobacco products: a regulated market model. Tob Control 2003;12:374-82.

9 Callard C, Thompson D, Collishaw N. Transforming the tobacco market: why the supply of cigarettes should be transferred from for-profit corporations to non-profit enterprises with a public health mandate. Tob Control 2005:14:278-83.

10 Malone RE. Imagining things otherwise: new endgame ideas for tobacco control. Tob Control 2010;19:349-50.
11 Thomson G, Wilson N, Blakely T, et al. Ending appreciable tobacco use in a nation: using a sinking lid on supply. Tob Control 2010;19:431-5.

12 Khoo D, Chiam Y, Ng P, et al. Phasing-out tobacco: proposal to deny access to tobacco for those born from 2000. Tob Control 2010;19:355-60.

13 Daynard RA. Doing the unthinkable (and saving millions of lives). Tobacco Control 2009;18:2-3.

14 Proctor RN. Golden holocaust: origins of the cigarette catastrophe and the case for abolition. Berkeley, CA: University of California Press, 2012.

15 Zeller M, Hatsukami D, Strategic Dialogue on Tobacco Harm Reduction Group. The strategic dialogue on tobacco harm reduction: a vision and blueprint for action in the US. Tob Control 2009;18:324-32.

16 Calantzopoulos A. Remarks by Andre Calantzopoulos, Chief Operating Officer, Philip Morris International. Investor Day. Lausanne, Switzerland, 21 June 2012:11-15. https://www. media-server.com/m/instances/8hinb6wm/items/ v2b4bx9m/assets/m8djui39/0/file.pdf (accessed 26 Jan 2013).

17 Peters AS. The nicotine inhaler. http://www. quitnet. com/library/guides/nrt/inhaler.jtml (accessed 26 Jan 2013).

18 Henningfield JE, Zaatari GS. Electronic nicotine delivery systems: emerging science foundation for policy. Tob Control 2010;19:89-90.

19 American Nonsmokers'Rights Foundation. Smokefree status of workplaces and hospitality venues around the world. 2 January 2013. http://www.no-smoke. org/pdf/internationalbarsandrestaurants.pdf (accessed 26 Jan 2013).

20 Cigarette plain packaging laws come into force in Australia. 1 December 2012. http://www. guardian. co.uk/world/2012/dec/01/ plain-packaging-australian-cigarette-tobacco (accessed 26 Jan 2013).

21 Cigarette warnings in Uruguay. http://www. smoke-free.ca/warnings/Uruguay\%20-\%20health\% 20warnings.htm (accessed 26 Jan 2013).

22 Chapman S. The case for a smoker's license. PLoS Med 2012;9:e1001342.

23 Benowitz NL, Henningfield JE. Reducing the nicotine content to make cigarettes less addictive. Tob Control 2013:22:i14-i17.

24 Borland R. Minimising the harm from tobacco use: finding the right regulatory framework. Tob Control 2013;22:i6-i9

25 Callard C, Collishaw N. Supply-side options for an endgame for the tobacco industry. Tob Control 2013;22:i10-i13.

26 Wilson N, Thomson G, Edwards R, et al. Potential advantages and disadvantages of an endgame strategy: a "sinking lid" on tobacco supply. Tob Control 2013;22:118-i21.

27 Berrick AJ. The tobacco-free generation proposal. Tob Control 2013;22:i22-i26.

28 Proctor RN. Why ban the sale of cigarettes? The case for abolition. Tob Control 2013;22:i27-i30.

29 Rabe B. Political impediments to a tobacco endgame. Tob Control 2013;22:i52-i54.

30 Isett K. In and across bureaucracy: structural and administrative issues for the tobacco endgame. Tob Control 2013;22:158-i60.

31 Reuter P. Can tobacco control endgame analysis learn anything from the U.S. experience with illegal drugs? Tob Control 2013;22:i49-i51.

32 Thomas BP, Gostin LO. Tobacco endgame strategies: challenges in ethics and law. Tob Control 2013;22:i55-i57.

33 Tam J. Cultivating the next generation of tobacco endgame advocates. Tob Control 2013;22:i47-i48. 